\title{
Charge Scheduling Strategies for Managing an Electric Vehicle Fleet Parking
}

\author{
Roberto Álvaro, Jesús Fraile-Ardanuy
}

\section{INTRODUCTION}

According to World Health Organization (WHO), air pollution in most cities worldwide is responsible for the significant increase in respiratory and cardiovascular diseases on the urban population. Comparing the current situation with previous years, air pollution has worsened in most of the cities under study [1]. Several factors contribute to this effect, mainly the utilization of fossil fuels (coal, natural gas, etc.) for building heating and the use of private internal combustion engine (ICE) vehicles.

Currently, the world's population is around 7.2 billion people and more than a half (53\%) is living in cities [2], but it is expected to increase to 9.6 billion by 2050, increasing the percentage of total urban population to around 70-75\% [3]. For this reason, the reduction of $\mathrm{CO}_{2}$ emissions and improving air quality in urban areas are fundamental points to be solved in the following years.

Governments around the world are promoting different strategies to reduce greenhouse gas emissions (GHG) in the urban areas, supporting energy-efficient housing and cleaner transportation systems. One way to become more sustainable is to promote public transportation, bicycling and walking in the cities, reducing the total number of vehicles in the streets. The other way is to boost the transition from ICE vehicles to more efficient ones, particularly to electric vehicles (EVs) [4].

Initially, this transition can be led by public or private urban fleets, like postal and delivery carriers, taxi cabs, fast-food couriers, etc., because most of these vehicles travel short and repetitive routes, suitable for current $\mathrm{EV}$ technology available.

Replacing conventional fleet vehicles with EVs will have a number of positive effects that affect the whole urban population, as reducing GHG emissions and noise [5]. But EVs can also offer additional financial, operational and environmental benefits for the fleet operators, like reduced maintenance, lower energy costs, fiscal incentives, enhanced brand image, etc.
The strongest argument against EVs is their limited range. The current range is between $75 \mathrm{~km}$, for a simple microvans operating in short urban trips [6] to more than $300 \mathrm{~km}$ for fullsized electric cars used as EV taxi cabs [7], [8]. These type of vehicles require frequent charging [9] at fleet parking areas, where a limited number of charging stations (CSs) are installed. An adequate charging algorithm must be implemented to manage the charging process efficiently, avoiding having some EVs out of energy and not reaching their final destination.

In this paper, different CS scheduling strategies for an efficient recharging process management of an EV fleet in a centralized parking are presented. In Section II, the optimization problem is defined. Section III presents different optimization algorithms to recharge EVs with a limited number of CSs. These algorithms are applied to a company EV fleet that operates in the urban gardening and landscaping maintenance sector, and the results are presented in Section IV. Finally, the main conclusions are summarized in the last Section.

\section{PROBLEM FoRMULATION}

Fig. 1 presents an overview of the implemented system. The company operates a fleet of $J$ EVs that must be recharged in its parking lot, where $C$ CSs are installed. Each $j$-th EV arrives at the parking lot at $K_{\text {in }}(j)$ and leaves it at $K_{\text {out }}(j)$, demanding an amount of energy $E_{\text {dem }}(j)$ to be recharged during this time period. This time period is highlighted at the bottom of Fig. 1 by light blue boxes and the two dark blue boxes denote the beginning $\left(K_{\text {in }}(j)\right)$ and the end $\left(K_{\text {out }}(j)\right)$ of this period.

Each CS can provide, for each period of time $k$, a certain amount of energy, $E_{\max }$ with a charging efficiency of $\mu_{\mathrm{c}}$.

The amount of time slots required by the $j$-th $\mathrm{EV}$ to be charged is defined by $V_{\operatorname{dem}}(j)$ and is evaluated by:

$$
V_{\text {dem }}(j)=\operatorname{ceil}\left(E_{\text {dem }}(j)\left(\mu_{c} \cdot E_{\max }\right)\right)
$$




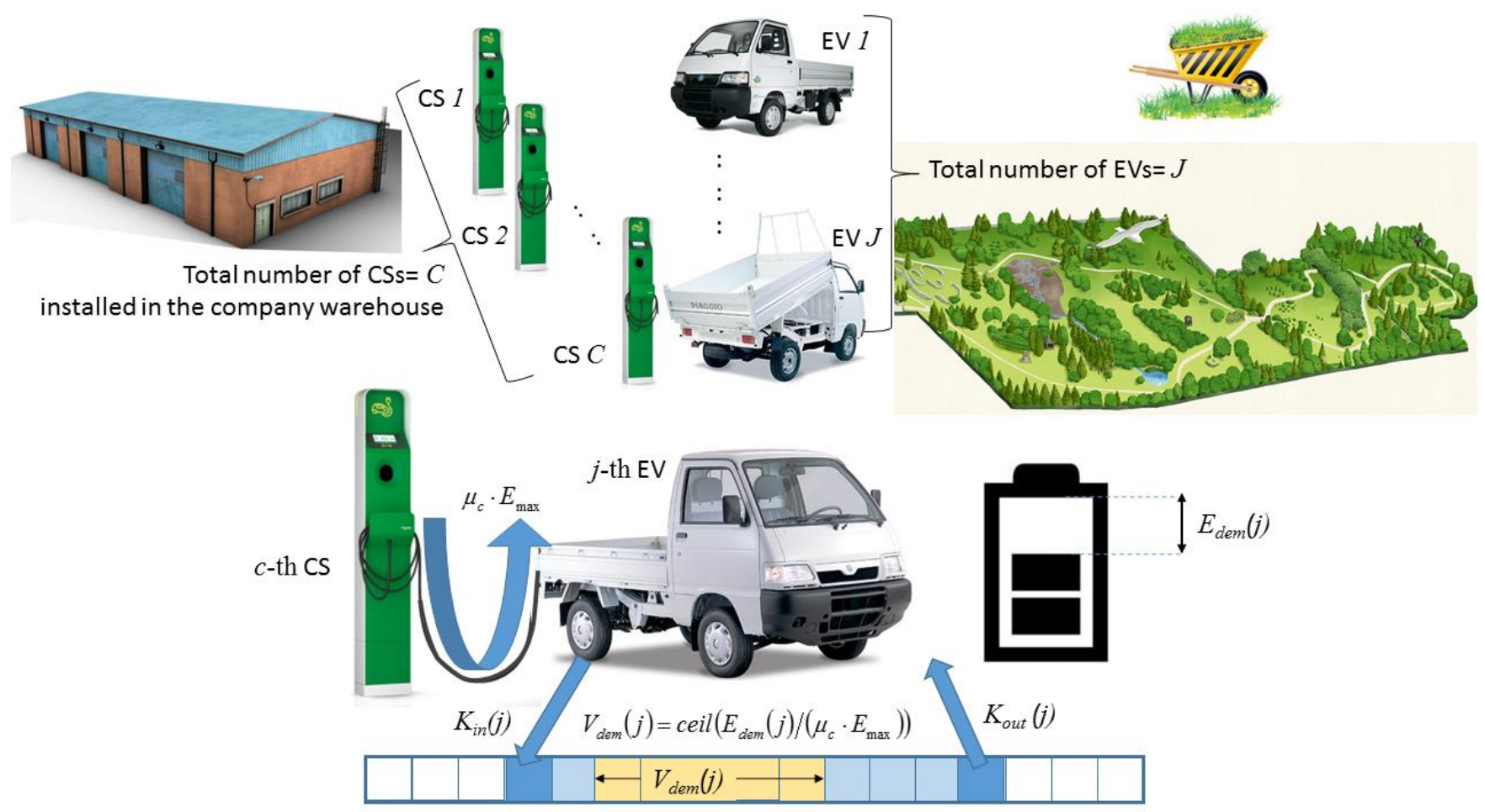

Fig. 1. System Implementation. Main variables and parameters.

Where $\operatorname{ceil}(x)$ rounds $x$ to the nearest higher integer. Equation (1) assumes that every CS can charge an EV at the maximum energy rate during each time slot. The time period $V_{\mathrm{dem}}(j)$ is also shown in Fig. 1 (yellow boxes at the bottom of the Figure).

The proposed CS scheduling algorithm maximizes the total number of vehicles fully charged at the end of the time horizon $K$. In this case, the solution is constrained to be an integer value, therefore, a mixed-integer programming (MIP) problem must be solved.

The objective function to maximize is given by:

$$
\max \sum_{\mathrm{j}} e v_{c h}(\mathrm{j})
$$

Subject to the following restrictions:

$$
\begin{gathered}
v(c, j, k) \leq c_{\text {disp }}(c, j) ; \quad \forall c, \forall j, \forall k \\
\sum_{c} c_{\text {disp }}(c, j) \leq 1 ; \quad \forall j \\
\sum_{\mathrm{j}} v(c, j, k) \leq 1 ; \quad \forall c, \forall k \\
\sum_{\mathrm{c}} \sum_{\mathrm{k}} v(c, j, k)=V_{\text {dem }}(j) e v_{c h}(j) ; \quad \forall j \\
v(c, j, k)=0 ; \quad k<K_{\text {in }}(j) ; \quad k>K_{\text {out }}(j)
\end{gathered}
$$

Three decision variables are adjusted by the optimization algorithm: $v(c, j, k), c_{\text {disp }}(c, j)$ and $e v_{\mathrm{ch}}(j)$. Variable $v(c, j, k)$ is a binary decision variable which indicates that the $j$-th $\mathrm{EV}$ is connected to the $c$-th CS at time period $k$ and it is been charged $(v(c, j, k)=1)$. Binary variable $c_{\text {disp }}(c, j)$ determines the availability to charge the $j$-th EV at $c$-th CS and binary variable $e v_{\text {ch }}(j)$ indicates that $j$-th $\mathrm{EV}$ is fully-charged.

Analyzing the restriction equations, the first constraint, defined by (3), implies that the $j$-th EV can be connected to the $c$-th CS at time period $k$ if $c_{\text {disp }}(c, j)=1$. Restriction (4) determines that each EV can only be charged at one specific $\mathrm{CS}$; therefore, it is not allowed to assigned vehicles to more than one CS. Constraint (5) sets that, at each time period $k$, a CS can only provide service to a single vehicle. Equation (6) determines that the amount of time periods that the $j$-th EV needs to be charged is equal to $V_{\mathrm{dem}}(j)$ if it is finally fullycharged $\left(e v_{\mathrm{ch}}(j)=1\right)$ and it is equal to zero if it is not selected by the optimization algorithm to be charged $\left(e v_{\mathrm{ch}}(j)=0\right)$. Finally, restriction (7) implies that a vehicle can only be charged during the time interval in which it is parked.

\section{IMPROVING THE SCHEDULING ALGORITHMS}

If the number of EVs exceed the CSs capacity to fully recharge all of them, it is usually preferable to maximize the total amount of energy provided by the recharging system to the vehicles. In this case, the objective function (2) is weighted by $E_{\mathrm{dem}}(j)$, obtaining a new function:

$$
\max \sum_{\mathrm{j}} E_{d e m}(\mathrm{j}) \cdot e v_{c h}(\mathrm{j})
$$

A different problem arises when charging certain type of EVs may be preferred above others. For example, due to financial reasons, fleet operators are willing to maximize the charging system infrastructure, sharing it between fleet EVs 
and personal private EVs, but providing preference for the first type of vehicles above the others. If $\mathrm{J}$ ' is the total number of fleet EV vehicles and $J$ " is the number of private ones, the weighting variable included in the previous optimization function (8) is modified for private EVs:

$$
\begin{aligned}
& W(j)=\frac{K_{d e m}}{\sum_{i \in J^{\prime}} E_{d e m}(i)} E_{d e m}(j) \forall \mathrm{j} \subset \mathrm{J}^{\prime} \\
& K_{d e m} \leq \min \left(\mid E_{d e m}(j)-E_{d e m}\left(j^{\prime}\right)\right) \\
& j_{, j} j^{\prime} \subset J^{\prime}, E_{d e m}(j) \neq E_{d e m}\left(j^{\prime}\right)
\end{aligned}
$$

And the objective function (8) is transformed to:

$\max \left[\sum_{j=1}^{J} E_{d e m}(j) e v_{c h}(j)+\sum_{j=1}^{J *} \frac{K_{d e m}}{\sum_{i=1}^{J n} E_{d e m}(i)} E_{d e m}(j) e v_{c h}(j)\right]$

The first term in (10) is equal to function (8), but the second term, related to private EVs, have been weighted by a coefficient that implies that no possible combination of vehicles from group $\mathrm{J}$ " is preferred over a minimum increase in the energy charged in the EV fleet. This minimum increase, $K_{\text {dem }}$, is defined in (9) as the minimum absolute difference between terms from the fleet.

\section{CHARGING SCENARIOS}

To evaluate the proposed charging scheduling schemes in a real-world scenario, in this work the mobility information provided by a Spanish urban gardening maintenance company which operates an EV fleet for its daily trips around the different city gardens, is used.

The data consists of charging and mobility information from a set of 11 EVs from the fleet company, collected over one month.

This data provides the following information: EV identifier, date, arrival time, departure time, initial state of charge (SoC), final SoC, distance travelled and type of charger. All vehicles have a similar daily pattern, leaving the warehouse parking in the morning and returning back throughout the day. Vehicles are recharged in the parking whenever possible during their daily stops and, in the worst case, these vehicles will be fully charged during the longer night periods.

In this paper, three different scenarios for CS scheduling management during the daily stops are evaluated. Firstly, the optimization problem defined by (2) is applied to a group of 11 EVs from this fleet. It is observed from the data available that EVs have to come back to the parking lot during two hours and can be recharged during 8 different periods of 15 minutes each.

Secondly, the objective function defined in (8) is applied to the same set.

Finally, some company employees (and other company suppliers) use also other external private EVs. These vehicles can park at the same time and at the same place (warehouse parking) as company fleet vehicles. The last scenario analyses this situation. The optimization function defined in (10) is used to maximize the CSs utilization, considering two different types of vehicles: a set of 11 fleet vehicles and 5 additional private EVs. In this case, the algorithm must prioritize the energy charged into the EVs from the company fleet.

No vehicle shift from one CS to other is allowed in none of the analysed scenarios, therefore restrictions (3-7) are enforced.

Each CS provides a maximum amount of energy $E_{\max }$ equal to $3.3 \mathrm{kWh}$ in each time period, $k$, which implies a power of $13.2 \mathrm{~kW}$. The charging efficiency $\mu_{\mathrm{c}}$ employed is 0.95 [10].

\section{A. Algorithm functionality}

Initially, to test the first algorithm functionality, defined by (2), a simple test considering a single CS is analyzed. Table I shows the periods of time in which each EV from the fleet is located at the parking (defined by the variables, $K_{\text {in }}(j)$ and $\left.K_{\text {out }}(j)\right)$ and the demanded energy, $\left.E_{\operatorname{dem}}(j)\right)$. Taking into account the nominal recharge power, the number of time periods that this vehicle needs to be charged, $V_{\operatorname{dem}}(j)$, is evaluated by (1).

The results of the optimization algorithm are shown in the right side of Table I. For example, for the first time slot, $k=1$, $v(1, j, 1)=0$ for all vehicles except EV F9 for which $v(1,9,1)=1$, indicating than EV F9 is been charged by this specific CS. The rest of the results have been highlighted in this Table. The fully recharged vehicles are F9, F1 and F7. Vehicles are charged at the only available CS (CS1), therefore, $c_{\text {disp }}(1,1)=c_{\text {disp }}(1,7)=$ $c_{\text {disp }}(1,9)=1$ and $c_{\text {disp }}(1, j)=0$ for the rest of EVs. Since vehicles can only be charged at one CS, due to restriction (4), $c_{\text {disp }}(\mathrm{c}, \mathrm{j})=1$ for a $\mathrm{CS}$, this implies $e v_{\mathrm{ch}}(\mathrm{j})=1$ $\left(e v_{c h}(1)=e v_{\mathrm{ch}}(7)=e v_{\mathrm{ch}}(9)=1\right.$ and zeros for the rest of EVs, $\left.e v_{\mathrm{ch}}(\mathrm{j})=0\right)$.

\section{TABLE I. EV FLEET AVAIIABILITY AND CHARGING SCHEDULING FOR A} SINGLE CS

\begin{tabular}{|c|c|c|c|c|c|c|c|c|c|c|c|c|}
\hline $\begin{array}{c}\text { EV } \\
\text { ID }\end{array}$ & $\begin{array}{c}\text { Energy } \\
(\mathbf{k W h})\end{array}$ & $\mathrm{K}_{\text {in }}$ & $\mathrm{K}_{\text {out }}$ & $\mathrm{V}_{\text {dem }}$ & 1 & 2 & 3 & 4 & 5 & 6 & 7 & 8 \\
\hline F1 & $\mathbf{9}$ & $\mathbf{1}$ & $\mathbf{6}$ & $\mathbf{3}$ & & & F1 & F1 & F1 & & & \\
\hline F2 & 13 & 1 & 7 & 5 & & & & & & & & \\
\hline F3 & 6 & 5 & 7 & 2 & & & & & & & & \\
\hline F4 & 8 & 5 & 8 & 3 & & & & & & & & \\
\hline F5 & 15 & 2 & 6 & 5 & & & & & & & & \\
\hline F6 & 12 & 1 & 8 & 4 & & & & & & & & \\
\hline F7 & 9 & $\mathbf{3}$ & $\mathbf{8}$ & $\mathbf{3}$ & & & & & & F7 & F7 & F7 \\
\hline F8 & 12 & 4 & 7 & 4 & & & & & & & & \\
\hline F9 & $\mathbf{5}$ & $\mathbf{1}$ & $\mathbf{6}$ & $\mathbf{2}$ & F9 & F9 & & & & & & \\
\hline F10 & 12 & 2 & 8 & 4 & & & & & & & & \\
\hline F11 & 9 & 1 & 3 & 3 & & & & & & & & \\
\hline
\end{tabular}




\section{B. Algorithm results for $5 \mathrm{CSs}$}

In this section the different optimization algorithms are tested in the real system, where there are 5 CSs currently available in this particular warehouse parking.

Table III shows the charging scheduling for the first scenario. The optimization of the objective function (2), maximizes the total number of $\mathrm{EV}$ charged (the charging algorithm can recharge, in this time horizon, 10 different EVs from the company fleet).

TABLE II SCHEDULE FOR OBJECTIVE FUNCTION (2)

\begin{tabular}{|c|c|c|c|c|c|c|c|c|c|}
\hline \multirow[b]{2}{*}{ Charging Stations } & CS1 & & F10 & F10 & F10 & F10 & F4 & F4 & F4 \\
\hline & CS2 & F1 & F1 & F1 & F9 & F9 & F3 & F3 & \\
\hline \multirow{3}{*}{ Fully $C$} & CS3 & F2 & F2 & $\mathrm{F} 2$ & $\mathrm{~F} 2$ & $\mathrm{~F} 2$ & F7 & F7 & F7 \\
\hline & CS4 & & F5 & F5 & F5 & F5 & F5 & & \\
\hline & CS5 & F11 & F11 & F11 & F8 & F8 & F8 & F8 & \\
\hline
\end{tabular}

Table IV presents the charging scheduling for the second scenario. In this case, the optimization of the objective function (8), maximizes the total energy charged in the EVs. It is observed that both charging scheduling (maximizing objective functions (2) or (8)) charge the same number of EVs: 10 EVs. However, in the second scenario, the optimization of the objective function (8) enforces the maximum amount of energy recharged by the system, up to a total of $101 \mathrm{kWh}$ instead of the $98 \mathrm{kWh}$ charged when the objective function (2) is used.

TABLE III. SCHEDULE FOR OBJECTIVE FUNCTION (8)

\begin{tabular}{|c|c|c|c|c|c|c|c|c|c|}
\hline \multirow[b]{2}{*}{ Charging Stations } & CS1 & & F5 & F5 & F5 & F5 & F5 & & \\
\hline & CS2 & F9 & F9 & F10 & F10 & F10 & F3 & F3 & F10 \\
\hline \multirow{3}{*}{$\begin{array}{l}\text { Fully Charged EVs: } \\
\qquad 10\end{array}$} & CS3 & F2 & F2 & $\mathrm{F} 2$ & $\mathrm{~F} 2$ & $\mathrm{~F} 2$ & F7 & F7 & F7 \\
\hline & CS4 & F6 & F6 & F6 & F8 & F8 & F8 & F8 & F6 \\
\hline & CS5 & F11 & F11 & F11 & & $\mathrm{F} 4$ & F4 & F4 & \\
\hline
\end{tabular}

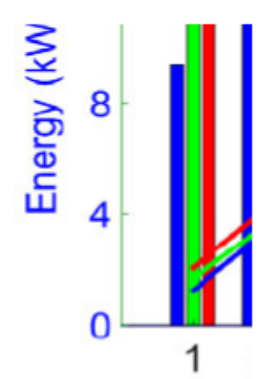

Fig. 2. Total energy recharged in each scenario.
Figure 2 shows the amount of energy recharged in the EVs in each time slot, denoted by bars in the graph (and scaled on the left vertical blue axis), and the cumulative energy recharged by the system, shown by lines in the same graph (and scaled on the right vertical green axis).

It has been observed in the previous both scenarios, that there are some idle time slots that can be used for recharging additional vehicles. Table $\mathrm{V}$ shows the charging scheduling for an additional scenario, where the charging management system can also try to charge other private EVs, maximizing the total energy recharged and using the free (not-assigned) time slots to charge additional private EVs.

Information related to the original EV fleet is shown at the top of the table (vehicle ID, Energy, $K_{\text {in }}, K_{\text {out }}$ and $V_{\text {dem }}$ ). The mobility information related to the external private EVs is shown at the center of the table. Finally, the result of the optimization process determines the occupation for the 5 CSs. This occupation information is presented at the bottom of the table.

TABLE IV. SCHEDULE FOR OBJECTIVE FUNCTION (10)

\begin{tabular}{|c|c|c|c|c|c|c|c|c|c|c|c|c|}
\hline \multicolumn{5}{|c|}{ EV Fleet } & \multicolumn{8}{|c|}{ Time Period } \\
\hline $\begin{array}{l}\text { EV } \\
\text { ID }\end{array}$ & $\begin{array}{c}\text { Energy } \\
\text { (kWh) }\end{array}$ & $\mathbf{K}_{\text {in }}$ & $K_{\text {out }}$ & $V_{\text {dem }}$ & 1 & 2 & 3 & 4 & 5 & 6 & 7 & 8 \\
\hline F1 & 9 & 1 & 6 & 3 & \multicolumn{3}{|c|}{ Charged CS5 } & & & & & \\
\hline F2 & 13 & 1 & 7 & 5 & \multicolumn{5}{|c|}{ Charged CS3 } & & & \\
\hline F3 & 6 & 5 & 7 & 2 & & & & & \multicolumn{2}{|c|}{$\mathrm{CS}_{2}$} & & \\
\hline F4 & 8 & 5 & 8 & 3 & & & & & \multicolumn{4}{|c|}{ Charged CS3 } \\
\hline F5 & 15 & 2 & 6 & 5 & \multicolumn{6}{|c|}{ Charged in CSI } & & \\
\hline F6 & 12 & 1 & 8 & 4 & \multicolumn{3}{|c|}{$\mathrm{CS} 4$} & & & & & \\
\hline F7 & 9 & 3 & 8 & 3 & & & & & & & & \\
\hline F8 & 12 & 4 & 7 & 4 & & & & \multicolumn{4}{|c|}{ Charged in CS4 } & \\
\hline F9 & 5 & 1 & 6 & 2 & & & & & & & & \\
\hline F10 & 12 & 2 & 8 & 4 & & & & & \multicolumn{4}{|c|}{ Charged in CS5 } \\
\hline F11 & 9 & 1 & 3 & 3 & & ged & & & & & & \\
\hline
\end{tabular}

Private External EVs

\begin{tabular}{|c|c|c|c|c|c|c|c|c|c|c|c|c|}
\hline P1 & 3 & 1 & 4 & 1 & CS1 & & & & & & & \\
\hline $\mathrm{P} 2$ & 5 & 5 & 7 & 2 & & & & & & & & \\
\hline P3 & 2 & 7 & 8 & 1 & & & & & & & & CS1 \\
\hline P4 & 8 & 1 & 3 & 3 & & & & & & & & \\
\hline P5 & 6 & 2 & 5 & 2 & & & & & & & & \\
\hline P6 & 9 & 3 & 6 & 3 & & & & & & & & \\
\hline \multirow{3}{*}{\multicolumn{4}{|c|}{ Charging Stations }} & CS1 & P1 & F5 & F5 & F5 & F5 & F5 & & P3 \\
\hline & & & & $\mathrm{CS} 2$ & F11 & F11 & F11 & F7 & F3 & F3 & F7 & F7 \\
\hline & & & & $\mathrm{CS} 3$ & $\mathrm{~F} 2$ & F2 & $\mathrm{F} 2$ & $\mathrm{~F} 2$ & F2 & F4 & F4 & F4 \\
\hline \multicolumn{4}{|c|}{ Fully Charged EVs: } & $\mathrm{CS} 4$ & F6 & F6 & F6 & F8 & F8 & F8 & F8 & F6 \\
\hline \multicolumn{4}{|c|}{12 (10 fleet-2private) } & CS5 & F1 & F1 & F1 & & F10 & F10 & F10 & F10 \\
\hline
\end{tabular}


There are a few free slots for external private vehicles to be charged. Thus, in the third scenario, objective function (10) charges two additional vehicles, $\mathrm{P} 1$ and $\mathrm{P} 3$, increasing the total amount of charged energy to $110 \mathrm{kWh}$.

\section{Demand full coverage}

It has been shown that the current available charging infrastructure is not able to charge all vehicles from the fleet with only 5 CSs during the available time slots ( 8 periods). It is possible to determine the minimum amount of extra CSs required to charge all EVs from the fleet (11 EVs) using the developed algorithms. This analysis can be extended to fix the extra number of CSs required to also charge the external private vehicles. This is done using objective function (10) and increasing the total number of CSs sequentially. Table VI sums up which vehicles are charged for different number of CSs. It can be seen that only an additional CS is required to fully charge all vehicles from the company fleet, while it is necessary to install a new one (a total of $7 \mathrm{CSs}$ ) to charge all EVs (company fleet and private ones).

\section{TABLE V. MINIMUM AMOUNT OF CSS TO CHARGE ALL EVS.}

\begin{tabular}{l|l|l|l|l|l|l|l|l|}
\multicolumn{7}{c|}{ Number of Charging Stations } \\
\hline & I & 2 & 3 & 4 & 5 & 6 & 7 \\
\hline F1 & & & & & & & \\
\hline F2 & & & & & & & \\
\hline F3 & & & & & & & \\
\hline F4 & & & & & & & \\
\hline F5 & & & & & & & \\
\hline F6 & & & & & & & \\
\hline F7 & & & & & & & \\
\hline F8 & & & & & & & \\
\hline F9 & & & & & & & \\
\hline F10 & & & & & & & \\
\hline F11 & & & & & & & \\
\hline P1 & & & & & & & \\
\hline P2 & & & & & & & \\
\hline P3 & & & & & & & \\
\hline P4 & & & & & & & \\
\hline P5 & & & & & & & \\
\hline P6 & & & & & & & \\
\hline
\end{tabular}

\section{CONCLUSIONS AND FUTURE WORK}

In this work, different charging scheduling algorithms for managing an EV fleet parking have been presented. This tool can be applied to EV fleets whose daily trips are short and repetitive, i.e. urban couriers. These algorithms have been tested on real data from an EV fleet with five CSs and they have also been applied to calculate the minimum amount of
CSs that are required to charge all the EVs, minimizing the cost of the deployment of the charging infrastructure.

The first algorithm maximize the total number of vehicles fully charged for a specific number of CSs. A modified version of this algorithm optimizes the total energy stored in the EV batteries. It has been observed that there are some idle time slots that can be used for recharging additional vehicles. A new charging strategy has been proposed in order to aggregate external vehicles without interfering in the total amount of energy charged into the fleet vehicles.

In this work, it is assumed that all mobility information are available at the beginning of the day, because all vehicles of the fleet perform repetitive trips. Future work include an algorithm modification to account for the stochastic variability of the arrival and departure period of the vehicles as well as the amount of energy demanded by each of them. EV charging schedule will also include both day and night charge and the electricity price variability.

\section{ACKNOWLEDGMENT} from:

The research leading to these results have received funding

- European Union Seventh Framework Programme (FP7/2007-2013) under grant agreement $n^{\circ} 270833$.

- Spanish Ministry of Economy and Competitiveness under INNPACTO 2012 grant agreement $n^{\circ}$ IPT-20121072-12000.

\section{REFERENCES}

[1] WHO. "Air quality deteriorating in many of the world's cities". http://www.who.int/mediacentre/news/releases/2014/air-quality/en/ (May, 12 $2^{\text {th }}, 2015$ )

[2] Demographia, "Demographia World Urban Areas. 11 $1^{\text {th }}$ Edition. 2015" http://www.demographia.com/db-worldua.pdf (May, 13 ${ }^{\text {th }}, 2015$ )

[3] UN, "Concise Report on the World Population Situation in 2014", http://www.un.org/en/development/desa/population/publications/pdf/tre nds/Concise $\% 20$ Report $\% 20$ on $\% 20$ the $\% 20$ World $\% 20$ Population $\% 20$ Sit uation $\% 202014 /$ en $p d f$ (May, 12 $\left.{ }^{\text {th }}, 2015\right)$

[4] One Million Electric Vehicles by 2015, Department of Energy, USA http://www1.eere.energy.gov/vehiclesandfuels/pdfs/1 million electric v ehicles rpt.pdf (May, 12 $\left.{ }^{\text {th }}, 2015\right)$

[5] NYC Taxi \& Limousine Commission, "Take Charge. A Roadmap to Electric New York City http://www.nvc.gov/html/tlc/downloads/pdf/electric taxi task force re port 20131231.pdf (May, 13 $\left.{ }^{\text {th }}, 2015\right)$

[6] Piaggio Porter Technical Data http://www.piaggioporter.co.uk/electric.htm, (May, 15 ${ }^{\text {th }}, 2015$ )

[7] BYD e6 Technical Data, http://www.byd.com/na/auto/e6.html (May, $15^{\text {th }}, 2015$ )

[8] Tesla Model S Technical Data, http://www.teslamotors.com/models (May, 15 ${ }^{\text {th }}, 2015$ )

[9] D. Knutsen, O. Willén, A study of Electric Vehicle Charging Patterns and Range Anxiety, Uppsala Universitet, 2013, http://www.divaportal.org/smash/get/diva2:626048/FULLTEXT01.pdf (May, 13 ${ }^{\text {th }}, 2015$ )

[10] M. De Gennaro, E. Paffumi, H. Scholz, G.Martini, "GIS-driven analysis of e-mobility in urban areas: An evaluation of the impact on the electric energy grid", Applied Energy, vol. 124, pp. 94-116, July 2014. 